\title{
Impact of rapid-hardening cements on mechanical properties of cement bitumen emulsion asphalt
}

\author{
Xing Fang • Alvaro Garcia • Frank Winnefeld • \\ Manfred N. Partl · Pietro Lura
}

Received: 26 June 2014 / Accepted: 19 December 2014/Published online: 7 January 2015

(C) RILEM 2015

\begin{abstract}
Cement bitumen emulsion asphalt (CBEA) is obtained by mixing bitumen emulsion, cement, aggregates and filler at ambient temperature. CBEA is thought to be a promising substitute for hot mix asphalt because of its low environmental impact and cost-effectiveness. Disadvantages of this material are the long time required to reach its full strength and the inadequate understanding of the hardening mechanisms. This study aims at accelerating the development of mechanical properties of CBEA by using rapid-hardening cements while at the same time gaining a deeper understanding of the role of cement in CBEA. With this purpose, cold mix asphalt mixtures with cationic and anionic emulsions and
\end{abstract}

X. Fang $(\varangle) \cdot$ A. Garcia · F. Winnefeld .

M. N. Partl · P. Lura

Empa, Swiss Federal Laboratories for Materials Science and Technology, 8600 Duebendorf, Switzerland

e-mail: xing.fang@empa.ch

X. Fang $\cdot$ P. Lura

Institute for Building Materials (IfB), ETH Zurich,

Zurich, Switzerland

A. Garcia

Div. of Infrastructure and Geomatics, Faculty of

Engineering, University of Nottingham,

University Park NG7 2RD, UK

M. N. Partl

School of Architecture and the Build Environment, Highway and Railway Engineering, KTH Stockholm, Stockholm, Sweden different types of cement (ordinary Portland, calcium sulfoaluminate and calcium aluminate cement) were studied by means of isothermal calorimetry, measurements of water evaporation and Marshall tests. The results indicate that both anionic and cationic bitumen emulsions may affect the initial hydration rates of the cements used but have no significant influence on their degree of hydration after a few days. The addition of calcium sulfoaluminate and calcium aluminate cement to CBEA leads to mechanical properties after 1-day curing similar to those obtained with Portland cement after 1-week curing. Cement hydration dominates the strength gain, especially for rapid-hardening cements, and the type of cement influences both the amount of bound water and the rate of water evaporation from the CBEA.

Keywords Cement bitumen emulsion asphalt . Cationic bitumen emulsion - Anionic bitumen emulsion - Calcium sulfoaluminate cement $\cdot$ Calcium aluminate cement $\cdot$ Isothermal calorimetry

\section{Introduction}

Cold mix asphalt consists of bitumen emulsion, water, unheated aggregates and filler. This material has low environmental impact and is cost-effective [1-3]. However, it has rarely been used as structural layer for heavy-duty pavements $[2,3]$, mainly because of the 
long time (several weeks) required to reach its full strength [4], resulting in inadequate performance (inferior early strength and high porosity) compared with conventional hot mix asphalt (HMA) $[3,5,6]$.

In order to improve the early performance of cold mix asphalt, cement can be added to the mixture: 1-3\% of cement (by mass) significantly improve the early mechanical properties [7] and the fully cured material acquires comparable mechanical properties to an equivalent HMA [3, 8, 9]. Research on these composite materials, also called cement-asphalt emulsion composite (CAEC) [10, 11], cold bituminous emulsion mixture (CBEM) [4, 6], cementemulsion treated mixture (C-ETM) [12], cementbitumen treated material (CBTM) [13], started in the 1970s. In all of these materials, the primary binder is bitumen while cement is used as an admixture. Extensive research has also been carried out on cement asphalt mortar (CA mortar) [14, 15], in which cement is the primary binder and bitumen is an additive. CBEA shares characteristics of both cement and asphalt concrete $[16,17]$. In particular, compared with conventional HMA, CBEA has higher deformation resistance and lower temperature susceptibility [10]. Additionally, the introduction of cement in cold mix asphalt accelerates emulsion breaking [5], because cement hydration consumes water in the emulsion and meanwhile it increases its alkalinity. In particular, when a cationic bitumen emulsion is used, the cationic emulsifiers are supposed to become ineffective as soon as they come in contact with a very alkaline solution [18], resulting in balling of bitumen and inadequate coating of aggregates. This will consequently increase the stripping potential and decrease the durability of the cold mix asphalt.

By using rapid-hardening cements, the strength gain of CBEA may be accelerated. However, only in a couple of studies [19-21] blends of calcium aluminate cements (CAC) and calcium sulfate or calcium sulfoaluminate (CSA) cements were used to obtain rapid hardening mixtures. In Ref. [9] it was observed that the mechanical properties of CBEA are related to the amount of evaporable water still present in the mixture. Therefore, it may be possible to increase the early strength of CBEA by using CSA and CAC not only because of their rapid setting and hardening (a process in which hydration products form bridges between the aggregates), but also because they bind a higher amount of water than the hydration products of ordinary Portland cement (OPC). For example, ettringite (the main hydration product of CSA cement) contains 32 molecules of water in its crystal structure and aluminium hydroxide gel has both bound and adsorbed water [22]. Meanwhile, compared with OPC, the $\mathrm{CO}_{2}$ emissions can be substantially decreased by using CSA and CAC [23, 24].

This research aims at understanding the role of cement in CBEA. In particular, the objective of this work is to study the influence of bitumen emulsion on cement hydration. The focus is on the degree of hydration of the cement and on the amount of water bound by cement hydration products. By further monitoring the water content of CBEA during the curing process, the residual evaporable water content was quantified. Finally, when the development of cement hydration and moisture content of the mixtures are correlated with the mechanical properties, the contribution of cement hydration to the strength development of CBEA can be assessed. In particular, the role of rapid-hardening cement in the early performance of CBEA can be investigated by comparison with OPC.

\section{Materials and methods}

\subsection{Materials}

A uniform dense aggregate gradation for asphalt concrete AC-8 was used in this research (EN 13043:2002/AC, see Fig. 1). The aggregates were quarry material (quartz,

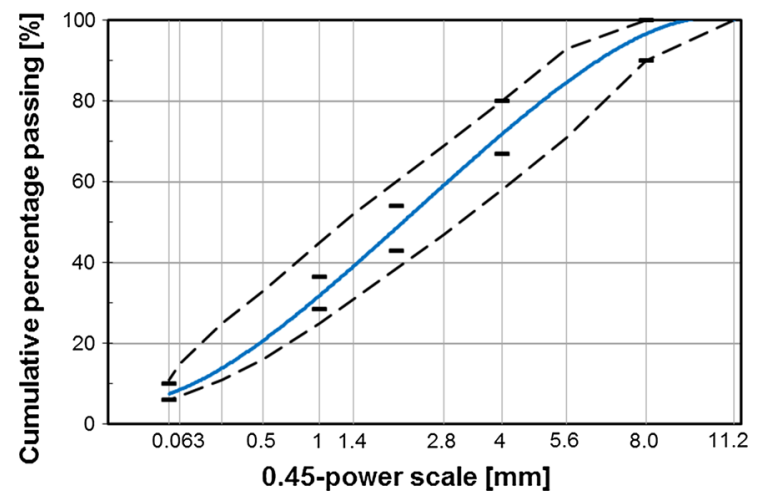

Fig. 1 Size distribution of the aggregates $(0 / 8)$ in the cold mix asphalt concrete (black curve upper and lower limit of specification. The short horizontal tick marks are control points for asphalt mixing plant) 
size between 2 and $8 \mathrm{~mm}$, density of $2,770 \mathrm{~kg} / \mathrm{m}^{3}$ ), crushed sand (quartz, size between 0.063 and $2 \mathrm{~mm}$, density of $2,688 \mathrm{~kg} / \mathrm{m}^{3}$ ), and limestone filler (size $<0.063 \mathrm{~mm}$ and density of $2,638 \mathrm{~kg} / \mathrm{m}^{3}$ ). The total amount of filler in the mixture was $6 \%$ by mass of dry mineral mixture (aggregates + filler).

Two types of commercially-available bitumen emulsions, with $60 \%$ of residual bitumen content, were used: an unmodified, rapid-setting cationic emulsion [residual bitumen after breaking: softening point of $63.6{ }^{\circ} \mathrm{C}$, penetration at $25^{\circ} \mathrm{C}$ of $\left.24(0.1 \mathrm{~mm})\right]$ and a solvent-free, slow-setting anionic emulsion [residual bitumen after breaking: softening point of $58.5^{\circ} \mathrm{C}$, penetration at $25^{\circ} \mathrm{C}$ of $\left.41(0.1 \mathrm{~mm})\right]$. Additionally, to facilitate the mixture preparation, tap water was added to the mixture.

Three types of cement were used: OPC CEM I $42.5 \mathrm{~N}$ (density of $3,130 \mathrm{~kg} / \mathrm{m}^{3}$ and Blaine fineness of $2,810 \mathrm{~cm}^{2} / \mathrm{g}$ ); CAC (density of $3,240 \mathrm{~kg} / \mathrm{m}^{3}$ and Blaine fineness of $3,710 \mathrm{~cm}^{2} / \mathrm{g}$ ); CSA cement, produced by blending $80 \%$ CSA clinker (density of $2,780 \mathrm{~kg} / \mathrm{m}^{3}$, Blaine surface area of $4,860 \mathrm{~cm}^{2} / \mathrm{g}$ ) and $20 \%$ of gypsum. The hydration and hardening behavior of rapid hardening cements is discussed in detail in $[23,25,26]$. The cement was added to the mixture by replacing either 0,3 or $6 \%$ of filler by weight of dry aggregate $(6 \%$ indicates all filler replaced). The chemical analysis and the phase composition of the cements and of the gypsum are listed in Table 1.

The mixture compositions by mass are summarized in Table 2. In the names of the mixtures throughout this paper, OPC, CSA and CAC designate ordinary Portland cement, calcium sulfoaluminate cement and calcium aluminate cement, respectively. The attached numbers 3 and 6 represent 3 and $6 \%$ cement by mass of dry aggregate, while $\mathrm{A}$ and $\mathrm{C}$ denote anionic and cationic bitumen emulsion, respectively. An example is CSA3C-7d, which refers to a cationic bitumen emulsion mixed with $3 \%$ calcium sulfoaluminate cement by mass of dry aggregate at a sample age of 7 days after compaction.

\subsection{Preparation of specimens}

The materials were mixed in a 20-L Hobart mixer. The amount of materials in each mixture was $5.95 \mathrm{~kg}$ and the temperature during mixing was $20 \pm 1{ }^{\circ} \mathrm{C}$. The raw materials were added to the bowl in this order: first the coarse aggregates, then water and emulsion, followed by the sand and finally, the filler and the cement. The materials were mixed during $1 \mathrm{~min}$.

One mix was used to make 9 cylindrical Marshall specimens with $101.6 \mathrm{~mm}$ diameter, approximately $70 \mathrm{~mm}$ height and 1,190 $\mathrm{g}$ of mass. Immediately after mixing and placing the specimens in the mould, they were compacted with 100 blows of the Marshall hammer, 50 on each side of the specimens.

The specimens, still in their moulds, were left in a humidity-controlled room (relative humidity $90 \pm 3 \%$ and temperature $20 \pm 1{ }^{\circ} \mathrm{C}$ ) for 1 day. After this, the specimens were demoulded and the lateral and bottom surfaces were sealed with aluminium foil to simulate the actual drying conditions of CBEA on the construction site. Then, the specimens were left in the humidity-controlled room during the required curing time of $1,3,7,14,21$ and 28 days. Throughout the curing period, water evaporation could occur from the specimens' upper side only.

Additionally, 3 HMA specimens were prepared with the residual bitumen obtained from both the anionic and the cationic emulsion. The bitumen was obtained by evaporating the water from the bitumen emulsion at $105{ }^{\circ} \mathrm{C}$ during $24 \mathrm{~h}$. Based on results presented in Ref. [29], it is assumed that this temperature is low enough to exclude any substantial effect of aging during temperature treatment on the stability of the HMA specimens. After the water evaporation step, aggregates and bitumen, without water, were heated to $160{ }^{\circ} \mathrm{C}$ and mixed in the same laboratory mixer used for making the CBEA. The exact mass of materials for each specimen before compaction was $1,190 \mathrm{~g}$ and the bitumen content was the same as in the CBEA samples. Finally, the specimens were compacted using 100 blows of the Marshall hammer, 50 on each flat face of the specimens.

\subsection{Isothermal calorimetry}

Isothermal calorimetry measurements were conducted at $20{ }^{\circ} \mathrm{C}$ with a TAM Air instrument (Thermometric) calibrated at $600 \mathrm{~mW}$. The rate of heat release was measured on mixtures containing the three types of cement and the two types of bitumen emulsions, with duplicate specimens for each mixture. The water to cement ratio (w/c) of the CBEA mixtures was 3.14 for mixtures with $3 \%$ cement and 1.57 for mixtures with $6 \%$ cement, including both the water in the emulsions 
Table 1 Chemical analysis and phase composition (by mass\%) of the cements and gypsum used

\begin{tabular}{|c|c|c|c|c|c|c|c|c|c|c|c|}
\hline & $\begin{array}{l}\text { OPC } \\
{[27]}\end{array}$ & $\begin{array}{l}\text { CSA } \\
{[28]}\end{array}$ & CAC & $\begin{array}{l}\text { Gypsum } \\
\text { [28] }\end{array}$ & $\begin{array}{l}\text { OPC } \\
{[27]}\end{array}$ & & $\begin{array}{l}\text { CSA } \\
{[28]}\end{array}$ & & CAC & & $\begin{array}{l}\text { Gypsum } \\
{[28]}\end{array}$ \\
\hline $\mathrm{CaO}$ & 61.9 & 36.1 & 38.0 & 33.30 & $\mathrm{C}_{3} \mathrm{~S}^{\mathrm{a}}$ & 56.1 & $\mathrm{C}_{4} \mathrm{~A}_{3} \mathrm{~S}$ & 62.8 & $\mathrm{CA}$ & 60.1 & \\
\hline $\mathrm{SiO}_{2}$ & 19.6 & 4.5 & 4.0 & & $\mathrm{C}_{2} \mathrm{~S}$ & 15.5 & CT & 5.7 & $\mathrm{C}_{12} \mathrm{~A}_{7}$ & 3.3 & \\
\hline $\mathrm{Al}_{2} \mathrm{O}_{3}$ & 5.1 & 45.0 & 38.4 & & $\mathrm{C}_{3} \mathrm{~A}$ & 4.8 & $\mathrm{C}_{2} \mathrm{AS}$ & 18.3 & $\mathrm{C}_{4} \mathrm{AF}$ & 11.1 & \\
\hline $\mathrm{Fe}_{2} \mathrm{O}_{3}$ & 2.9 & 1.5 & 16.5 & & $\mathrm{C}_{4} \mathrm{AF}$ & 11.5 & $\mathrm{CA}$ & 8.1 & $\mathrm{C}_{2} \mathrm{~S}$ & 10.9 & \\
\hline $\mathrm{MgO}$ & 2.3 & 0.91 & 0.47 & 0.30 & $\mathrm{MgO}$ & 1.0 & $\mathrm{CA}_{2}$ & 3.1 & $\mathrm{C}_{2} \mathrm{AS}$ & 3.5 & \\
\hline $\mathrm{K}_{2} \mathrm{O}$ & 1.0 & 0.35 & 0.12 & & $\mathrm{~K}_{2} \mathrm{SO}_{4}$ & 1.6 & MA & 1.8 & CT & 4.0 & \\
\hline $\mathrm{Na}_{2} \mathrm{O}$ & 0.26 & 0.07 & 0.07 & & $\mathrm{Na}_{2} \mathrm{SO}_{4}$ & 0.26 & Cs & & & & 3.3 \\
\hline $\mathrm{SO}_{3}$ & 3.0 & 8.6 & 0.06 & 46.70 & $\mathrm{~K}_{2} \mathrm{O}$ & 0.13 & $\mathrm{CsH}_{2}$ & & & & 96.7 \\
\hline $\mathrm{TiO}_{2}$ & 0.28 & 2.2 & 1.9 & & $\mathrm{Na}_{2} \mathrm{O}$ & 0.15 & $\mathrm{MgO}$ & 0.2 & $\mathrm{C}_{3} \mathrm{FT}$ & 0.9 & \\
\hline $\mathrm{P}_{2} \mathrm{O}_{5}$ & 0.20 & 0.08 & 0.06 & & $\mathrm{CaO}$ free & 0.27 & $\mathrm{CaO}$ free & 0.01 & $\mathrm{Ff}$ & 3.4 & \\
\hline $\mathrm{SrO}$ & 0.15 & 0.09 & & & $\mathrm{CaCO}_{3}$ & 4.8 & $\mathrm{~K}_{2} \mathrm{SO}_{4}$ & 0.06 & $\mathrm{MA}_{0.1} \mathrm{~F}_{0.9}$ & 0.9 & \\
\hline $\mathrm{Mn}_{2} \mathrm{O}_{3}$ & 0.00 & 0.02 & 0.05 & & $\mathrm{C}_{\mathrm{S}} \mathrm{H}_{2}$ & 4.0 & $\mathrm{Na}_{2} \mathrm{SO}_{4}$ & 0.01 & $\mathrm{C}_{20} \mathrm{~A}_{13} \mathrm{M}_{3} \mathrm{~S}_{3}$ & 1.8 & \\
\hline L.O.I. & 2.68 & 0.70 & 0.19 & 21.50 & & & & & & & \\
\hline Total & 99.4 & 100.2 & 99.7 & 101.8 & & 100.1 & & 100.1 & & 99.9 & 100.0 \\
\hline
\end{tabular}

${ }^{a}$ According to cement chemistry notation: $\mathrm{A}=\mathrm{Al}_{2} \mathrm{O}_{3}, \mathrm{C}=\mathrm{CaO}, \mathrm{F}=\mathrm{Fe}_{2} \mathrm{O}_{3}, \mathrm{~S}=\mathrm{SiO}_{2}, \mathrm{~s}=\mathrm{SO}_{3}, \mathrm{~T}=\mathrm{TiO}, \mathrm{f}=\mathrm{FeO}, \mathrm{M}=\mathrm{MgO}$

Table 2 Amount of materials by $100 \mathrm{~g}$ of mixture

${ }^{\text {a }}$ Percentage of cement by mass of dry aggregate

\begin{tabular}{llllll}
\hline Aggregate $(\mathrm{g})$ & Water $(\mathrm{g})$ & Emulsion $(\mathrm{g})$ & Filler $(\mathrm{g})$ & & \multicolumn{2}{l}{ Cement } \\
\cline { 4 - 6 } & & & & $(\mathrm{g})$ & $(\%)^{\mathrm{a}}$ \\
\hline \multirow{2}{*}{78.99} & 2.52 & 13.45 & 5.04 & 0 & 0 \\
& & & 2.52 & 2.52 & 3 \\
\hline
\end{tabular}

and the extra water added for workability. In addition to the CBEA mixtures, cold mix asphalt mixtures without cement and cement pastes with w/c 1.00 were measured for comparison purposes. A w/c of 1.00 was chosen to ensure enough water for full hydration (i.e., a further increase in w/c would not substantially affect hydration) and at the same time limit sedimentation of the cement pastes. About $20 \mathrm{~g}$ of freshly-mixed CBEA were inserted into glass vials of internal diameter $22.5 \mathrm{~mm}$, sealed with a tight lid and placed in the measuring cell. The rate of heat release was measured and integrated to obtain the cumulative heat release.

Upon cement hydration in the CBEA mixture, an amount of water becomes bound into the hydration products (both chemically and physically). In order to calculate the amount of free water present in the CBEA mixture, it is necessary to know the amount of water bound by the cement. The amount of bound water is proportional to the amount of cement present in the systems and to its degree of hydration. The

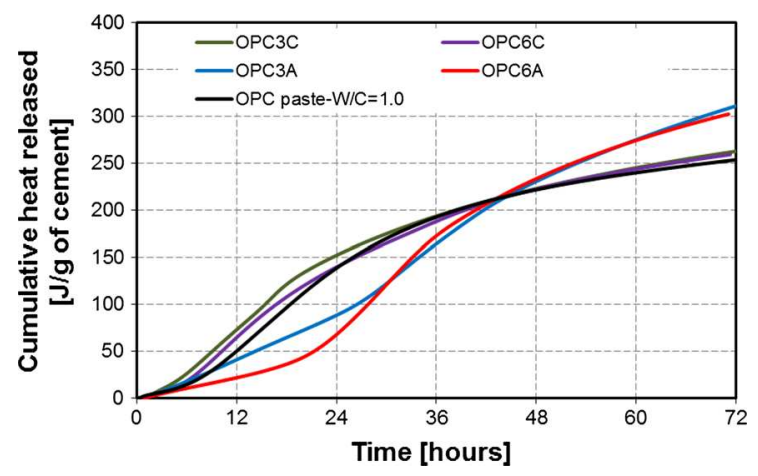

Fig. 2 Isothermal calorimetry of OPC: cationic emulsion with $3 \%$ (green) and $6 \%$ cement (purple), anionic emulsion with $3 \%$ (blue) and $6 \%$ cement (red) and cement paste with w/c 1.00 (black)

degree of hydration can be calculated by dividing the amount of heat developed at time $t$ (see Figs. 2, 3, 4) by the potential heat of the cement, which corresponds to the heat that is developed when all the cement has hydrated [30]: 


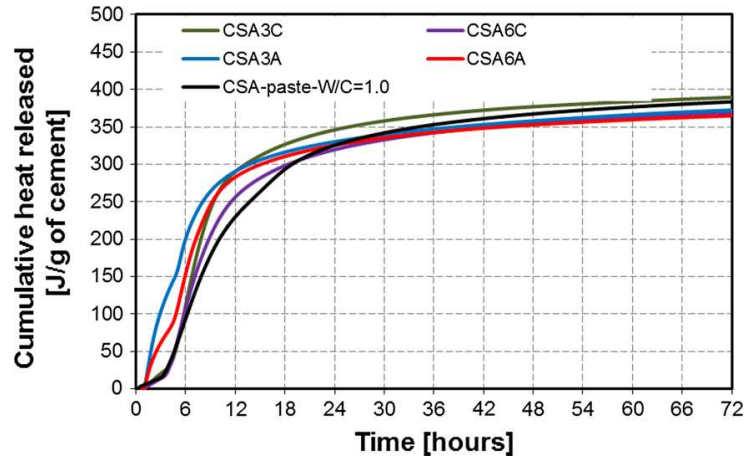

Fig. 3 Isothermal calorimetry of CSA: cationic emulsion with $3 \%$ (green) and $6 \%$ cement (blue), anionic emulsion with $3 \%$ (purple) and $6 \%$ cement (red) and cement paste with w/c 1.00 (black)

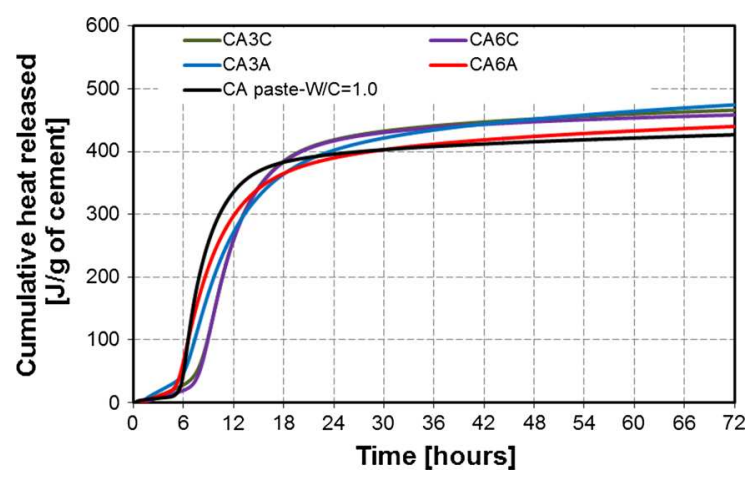

Fig. 4 Isothermal calorimetry of CAC: cationic emulsion with $3 \%$ (green) and $6 \%$ cement (blue), anionic emulsion with $3 \%$ (purple) and $6 \%$ cement (red) and cement paste with w/c 1.00 (black)

$\alpha(t)=\frac{H(t)}{H_{\mathrm{cem}}}$,

where $\alpha(t)$ is the degree of hydration at time $t$ and $H(t)$ is the cumulative heat measured at time $t$, expressed as $\mathrm{J} / \mathrm{g}$ of cement in the mixture and $H_{\text {cem }}$ is the total hydration heat of the cement, measured in $\mathrm{J} / \mathrm{g}$ of cement.

In the case of OPC, the potential heat can be calculated with good approximation with the following formula [22]:

$$
\begin{aligned}
H_{\mathrm{cem}}= & 517\left(\mathrm{C}_{3} \mathrm{~S}\right)+262\left(\mathrm{C}_{2} \mathrm{~S}\right)+1,144\left(\mathrm{C}_{3} \mathrm{~A}\right) \\
& +418\left(\mathrm{C}_{4} \mathrm{AF}\right),
\end{aligned}
$$

where the mass fractions of the main phases in OPC are given in Table 1 and the coefficients are in $\mathrm{J} / \mathrm{g}$ of cement. By using this formula, a value of $434 \mathrm{~J} / \mathrm{g}$ was calculated for the OPC used in this study.
For the CSA and CAC, the enthalpies of the reactions taking place during hydration are not as well established as for OPC. The approach followed in this case was measuring the heat evolved during 1 week on several cement pastes made of different $w / c$ with the same CSA and CAC used in the CBEA mixtures. After 7 days hydration, the degree of reaction was assessed with quantitative XRD [33]. With this approach, the potential heat values of $438 \mathrm{~J} / \mathrm{g}$ of cement reacted for CSA cement and $560 \mathrm{~J} / \mathrm{g}$ of cement reacted for CAC were calculated [33].

\subsection{Moisture loss and amount of trapped water}

The moisture loss of the Marshall specimens during curing was monitored by weighing them regularly during 28 days. Simultaneously, the Marshall specimens without cement were cured in a humiditycontrolled room (relative humidity $90 \pm 3 \%$ and temperature $20 \pm 1{ }^{\circ} \mathrm{C}$ ) for 4 months until mass loss due to evaporation stopped. Then they were crushed, loosened up at room temperature (the pieces were a maximum of $5 \mathrm{~mm}$ in size) and oven-dried at $105{ }^{\circ} \mathrm{C}$ to obtain the trapped water content. The trapped water was defined as the water adsorbed on the surfaces of aggregate and filler as well as the water trapped in the closed pores within the bitumen and that cannot evaporate. In this study, the amount of trapped water was determined from the average of 20 samples.

Because the cationic emulsion broke immediately when fine aggregates were added to the mixture, a considerable amount of water was lost during the compaction process. For this reason, it was possible to quantify the water content evolution only for the mixtures with anionic emulsion.

The initial water content in the mixtures is made up by the water in the bitumen emulsion and by the extra water used to wet the aggregates. As $2.52 \mathrm{~g}$ of water and $13.45 \mathrm{~g}$ of bitumen emulsion were added per $100 \mathrm{~g}$ of mixture and $40 \%$ by mass of the bitumen emulsion was composed by water (Table 2), the total initial mass percentage of water in the mixtures was $7.9 \%$.

In Ref. [9], it was shown that a decrease of the evaporable water content corresponded to an increase of the mechanical properties of the CBEA (see in particular Fig. 12 in [9]). Additionally, the residual water in CBEA gives an indication of stripping potential and moisture susceptibility of CBEA which are highly concerned by other researchers $[3,5,6]$. The 
water in the mixtures at a certain time $t$ can be classified in three categories: (i) residual water, consisting of residual evaporable water at time $t$ and of trapped water, (ii) physically bound water on the surface of the cement hydration products and (iii) chemically bound water within the hydration products [31]. The evaporable water is defined as the water within the capillary pores (ranging from a couple of $\mu \mathrm{m}$ to several $\mathrm{nm}$ in size) that are present in the hydration products of the cement and in the pores between the aggregates and the binder. The driving force for water evaporation is the difference in the water potential between the interior of the CBEA specimens and the air in the climate chamber, which progressively decreases due to evaporation and binding by cement hydration products, until equilibrium with the ambient relative humidity is eventually reached.

\subsection{Marshall tests}

The Marshall stability of CBEA was measured after 1, $3,7,14,21$ and 28 days. The tests were carried out immediately after the specimens had left the humiditycontrolled room and were completed within $10 \mathrm{~min}$. The testing room temperature was $20 \pm 1{ }^{\circ} \mathrm{C}$. Every Marshall stability value is the average of 3 specimens. The maximum force was taken as the Marshall stability value. In case a clear peak load could not be identified, the force measured when the displacement reached $10 \mathrm{~mm}$ was considered as the maximum force. The Marshall stability test was used since it is a conventional and widely applied test for asphalt mixtures and it gives both the maximum force (expressed by Marshall stability) and the flexibility (expressed by flow). While this study did not take the volumetric properties (void content, pore size and pore distribution) into consideration, it is expected that they will affect to a certain extent both the residual evaporable water content and the Marshall stabilities of the CBEA mixtures.

\section{Results}

\subsection{Isothermal calorimetry}

Mixtures without cement did not show any heat liberation. This confirms that all the heat liberated by the CBEA mixtures was the product of cement hydration. The rate of heat liberation and the cumulative heat of all the CBEA mixtures and of cement pastes with w/c 1.0 are shown in Figs. 2, 3, and 4.

Compared with the neat cement paste, in mixtures with anionic emulsion the OPC hydration was retarded, while no substantial retardation was observed with the cationic emulsion (Fig. 2). After a longer dormant period, the cumulative heat release of OPC in the presence of the anionic emulsion increased steadily and even surpassed the heat release of the cationic mixture and of the cement paste.

Both the anionic and the cationic emulsions accelerated the CSA cement hydration compared to the cement paste with w/c 1.00 (Fig. 3). However, no significant difference in the measured cumulative heat was observed between CBEA and neat cement paste after 24 h hydration.

Mixtures with cationic emulsion appear to retard slightly the CAC hydration, while a slight initial acceleration followed by a slower development of hydration heat is observed in the mixtures with anionic emulsion (Fig. 4). Also in this case, at 24 h hydration the difference between the CBEA mixtures and the neat cement paste is minimal.

The calculated degrees of cement hydration calculated by Eq. 1 in all CBEA mixtures in the first 3 days are shown in Table 3. CSA samples and CAC samples showed substantially higher hydration degree during the first 3 days and already after 1 day.

\subsection{Moisture loss and amount of trapped water}

The mass loss from all the mixtures with anionic emulsion as a function of time, corresponding to the amount of evaporated water, was measured by regular weighing. The results revealed that water evaporated

Table 3 Degree of hydration of the cement in the CBEA mixtures

\begin{tabular}{llll}
\hline Cement paste & \multicolumn{3}{l}{ Degree of hydration $(\%)$} \\
\cline { 2 - 4 } & $1 \mathrm{~d}$ & $2 \mathrm{~d}$ & $3 \mathrm{~d}$ \\
\hline OPC3A & 20 & 53 & 72 \\
OPC6A & 16 & 54 & 70 \\
CSA3A & 75 & 82 & 85 \\
CSA6A & 74 & 81 & 83 \\
CAC3A & 72 & 81 & 85 \\
CAC6A & 70 & 76 & 79 \\
\hline
\end{tabular}


rapidly during the first week after compacting, while only little moisture loss was observed from 7 to 28 days. In the absence of cement, the mass loss due to water evaporation was substantially higher, while in the mixtures with cement a part of the water became bound into the hydration products and could not evaporate, see Fig. 5. The amount of trapped water (obtained from weighing 20 duplicate samples) was $1.21 \%$. In this study, it is assumed that the amount of trapped water is the same for all mixtures, regardless of the amount and type of cement.

\subsection{Marshall stability}

In the case of the reference HMA, the Marshall stabilities of samples made with the residual bitumen obtained from the anionic and cationic emulsions were 25.9 and $36.5 \mathrm{kN}$, respectively. Cold mixture samples after drying showed lower stability than HMA obtained by evaporating the water is probably due to inadequate coating of aggregates, unevaporated water and presence of pores left by water evaporation.

The evolution of the Marshall stability with 0,3 and $6 \%$ of OPC is shown in Fig. 6. In case of mixtures without cement, only bitumen acts as a binder. The Marshall stabilities of mixtures with cationic emulsion and no cement show a linear growth in the stability (Fig. 6a). For the slow setting anionic emulsion with no cement, the test samples deformed under their own weight after demoulding (Fig. 6b) and the Marshall stabilities could not be determined. For this reason, only the trend of the measured stability is shown in Fig. 6b. The Marshall stability of mixtures with both cationic and anionic emulsions increased significantly

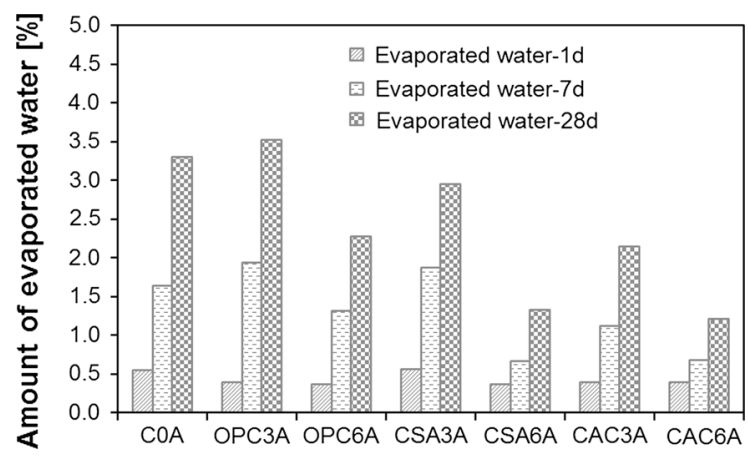

Fig. 5 Amount of evaporated water from Marshall specimens after 1, 7 and 28 days curing with the addition of cement. The stability increased steadily during the 28 days curing period except for OPC 3C, which remained almost constant after 7 days. The stability of OPC6C at 28 days was lower than that of the corresponding reference HMA, while the stability of test samples made with anionic emulsion (OPC3A and OPC6A) was similar to that of the reference HMA. In particular, after 1 day-curing, the stability of mixtures containing OPC and cationic emulsion is higher than the stability of mixtures without cement (see Fig. 6a). However, in case of mixtures with anionic emulsion, no significant differences in the Marshall stability were measured after 1 day between mixtures with and without OPC (see Fig. 6b).

The evolution of Marshall stability with curing time in test samples with CSA and CAC is shown in Figs. 7 and 8 , respectively. The early mechanical properties of CBEA with CSA and CAC were dramatically improved in comparison to mixtures with OPC. Mixtures made with the anionic bitumen emulsion appeared more homogenous than mixtures with the cationic emulsion. As a result, a linear growth of the Marshall stability was observed in CSA and CAC mixtures with the anionic emulsion. However, in the case of the cationic emulsion, the Marshall stability increased only during the first week and remained constant from 14 to 28 days. In the case of mixtures with $3 \%$ of cement, the stabilities varied from 10 to $15 \mathrm{kN}$ after 2 weeks curing time and were lower than the reference HMA. However, for mixtures with $6 \%$ cement, the stabilities at 28 days were lower than the reference HMA in the case of cationic emulsion, while for the anionic emulsion, the stabilities at 28 days were much closer to the reference HMA in the case of CSA cement or even higher in the case of CAC.

\section{Discussion}

4.1 Effect of emulsions on the initial rate of cement hydration

The initial retardation or acceleration observed in Figs. 2, 3, and 4 may be due to the $\mathrm{pH}$ of the bitumen emulsions [18], while no significant effect of the emulsion or of the bitumen could be observed on the later development of hydration. In Ref. [32], Tan et al. observed that both anionic emulsifiers and especially 
Fig. 6 Evolution of the Marshall stability with curing time (a OPC-C, b OPC-A, the Marshall stabilities of HMA samples, made with the residual bitumen obtained from the anionic and cationic emulsions, were 25.9 and $36.5 \mathrm{kN}$, respectively)

Fig. 7 Evolution of the Marshall stability with curing time (a CSA-C, b CSA-A, the Marshall stabilities of HMA samples, made with the residual bitumen obtained from the anionic and cationic emulsions, were 25.9 and $36.5 \mathrm{kN}$, respectively)

Fig. 8 Evolution of the Marshall stability with curing time (a CAC-C, b CAC-A, the Marshall stabilities of HMA samples, made with the residual bitumen obtained from the anionic and cationic emulsions, were 25.9 and $36.5 \mathrm{kN}$, respectively)
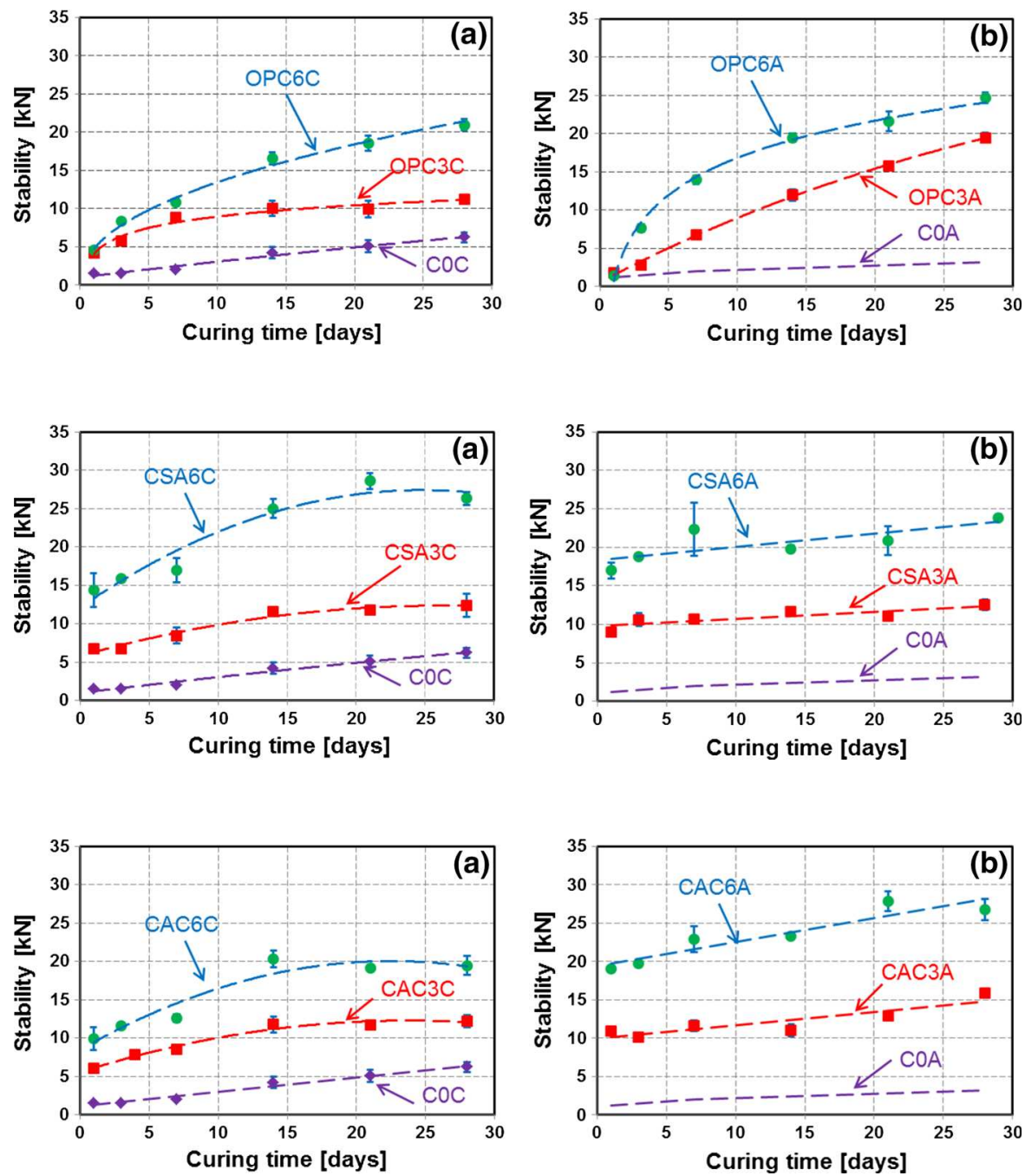

cationic emulsifiers retarded OPC hydration. However, a high concentration of emulsifiers and a low w/c of 0.28 were used in Ref. [32]. Also in Ref. [18] the addition of asphalt emulsions retarded OPC hydration; however, the effect was more pronounced for an anionic emulsion than for a cationic one, a result which agrees with Fig. 2. No data were found in the literature about the effect of bitumen emulsion on hydration of CSA and CAC.

\subsection{Degree of cement hydration}

As the initial w/c in the CBEA is rather high (3.14 for $3 \%$ cement and 1.57 for $6 \%$ cement), it is assumed in this study that the loss of water due to evaporation in the Marshall specimens has little impact on cement hydration in the first few days. Thus, the degree of hydration reached in the first 3 days is assumed to be equal to that of the mixtures hydrating in sealed condition in the isothermal calorimeter. In fact, considering the moisture loss by evaporation (Fig. 10), for the OPC mixtures after 3 days the w/c of the Marshall specimens is approximately between 0.9 and 1.7 .

After 3 days, the degree of hydration was considered to remain constant up to 28 days. Of course this approach will lead to an underestimation of the amount of bound water, which in reality will continuously grow, albeit at a low rate. However, since the degree of hydration at 3 days is already rather high, especially for the CSA and CAC, and considering the unknown effect of evaporation on the rate of hydration 
in the CBEA, this approach is considered to yield less uncertainties than a possible estimation of the degree of hydration at 28 days based on the rate of hydration in the first 3 days.

An alternative to this approach would be measuring directly the degree of hydration of the Marshall specimens, e.g. by thermogravimetry. This approach would have a high degree of uncertainty, due to the small amount of cement present in the mixture and especially to the superposition of mass losses due to the decomposition of the bitumen and of the hydration products.

\subsection{Water content evolution}

In this paper, the bound water (both chemically bound and physically bound, see categories (ii) and (iii) in Sect. 2.4) was determined according to the procedure explained in Ref. [33]. In particular, $1 \mathrm{~g}$ of fully reacted OPC binds a total amount of about $0.42 \mathrm{~g}$ of water, which corresponds to the results obtained with Powers model [31, 34]. For the CSA and the CAC, these values are much higher, 0.75 and $0.70 \mathrm{~g}$ of water, respectively.

The residual evaporable water in specimens used for the Marshall tests was calculated by subtracting the water that had already evaporated at time $t$, the water bound by the cement and the trapped water from the initial water present in the samples. Thus the residual evaporable water content was quantified as:

$p_{\text {ev }, \text { res }}(t)=p_{\text {tot }}-p_{\text {bou }}(t)-p_{\text {trap }}-p_{\text {ev }}(t)$,

where $p_{\mathrm{ev}}(t)$ is the percentage of water by initial mass of mixture that has evaporated at time $t, p_{\text {bou }}(t)$ is the percentage of water bound by the cement and $p_{\text {trap }}$ is the water trapped in the mixture. The residual evaporable water was quantified by Eq. 3 instead of quantifying it by oven drying because heating to temperatures higher than $100{ }^{\circ} \mathrm{C}$ for prolonged time would have both induced further hydration of the cement and loss of volatile components from the bitumen. Furthermore, $p_{\text {bou }}(t)$, the water bound by cement hydration, was quantified as [31, 34]:

$p_{\text {bou }}(t)=\lambda \cdot C \cdot \alpha(t)$,

where $\lambda$ is the amount of water bound by $1 \mathrm{~g}$ of cement, which is $0.42 \mathrm{~g} / \mathrm{g}$ of OPC, $0.75 \mathrm{~g} / \mathrm{g}$ of CSA and $0.70 \mathrm{~g} /$ $\mathrm{g}$ of CAC; $C$ is the percentage of cement in the mixture, 2.52 and $5.04 \%$ for mixtures with 3 and $6 \%$ of cement, respectively (see Table 2) and $\alpha(t)$ is the degree of hydration at curing time $t$ (Table 3 ). The water evaporated after 1 day, 3, 7 and 28 days are shown in Fig. 5 and the water bound by the cement (quantified according to Eq. 4) are shown in Fig. 9. In the case of C0A, obviously, the water could only be lost by evaporation. When cement was added, a part of the free water was bound by the cement. Thus the content of water available for evaporation was reduced. Figure 10 shows the content of residual evaporable water in every mixture studied, quantified by means of Eq. 3. The water content at 28 days varied from 1.5 to $3.5 \%$ (by initial mass of the Marshall specimens) and decreased very slowly after the first week.

Although the initial volumetric structure of the mixtures may influence to some extent the water evaporation, the amount of water evaporated and the kinetics of moisture loss are expected to be dominated by the total moisture content of the mixtures and by the amount of water that becomes bound into the hydration products of the cement. The amount of empty voids will on the contrary have a negligible effect on the water retention and evaporation. Based on these considerations, we believe that our set of experiments is still able to give a sufficiently complete picture about the evolution of the moisture content of the studied CBEA mixtures. The volumetric structure will certainly change from mixture to mixture; this will be the object of further studies.

\subsection{Contribution of bitumen emulsion and cement to mechanical properties of CBEA}

The linear stability growth of the samples without cement was probably caused by bitumen emulsion

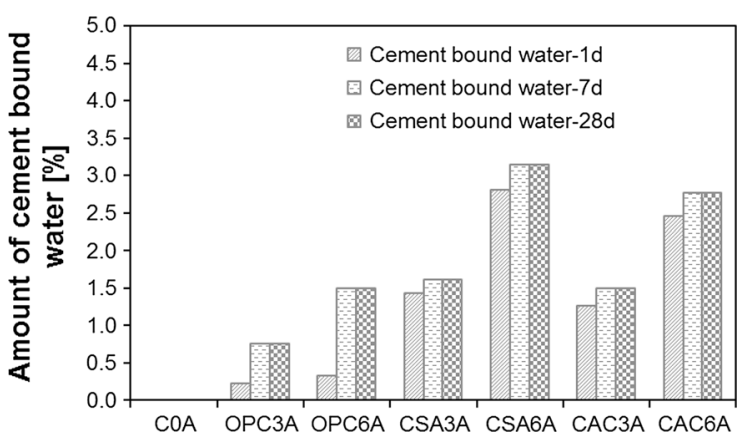

Fig. 9 Amount of water bound by hydration products of cement in Marshall specimens after 1,7 and 28 days curing 
breaking and by drying of water. The same results were also found by Terrel and Wang [16]. The stability of cationic samples after 1 day was increased by adding cement while anionic samples were not. This is caused by cement hydration. Evidence can be found in Fig. 2 which shows that in presence of cationic emulsion, a substantial amount of hydration occurred before 1 day, while in mixtures with anionic emulsion the hydration was retarded. On the contrary, for CSA and $\mathrm{CAC}$, the main hydration peak occurred well before 1 day (see Figs. 3, 4). A clear impact of this faster hydration is evident in Figs. 7 and 8, where the Marshall stability after 1 day was higher than for OPC mixtures. For example, in the cases of CSA3A and CSA6A, the stabilities after 1 day were already 83 and $77 \%$, respectively, of those at 28 days.

Figure 11a shows the Marshall force-displacement curve of OPC-containing specimens over time, according to which both the stiffness and the maximum force increased gradually as a function of time and cement hydration. On the contrary, mixtures with CAC (Fig. 11b) showed an almost constant stiffness, while the increase of maximum force after 1 day was limited.

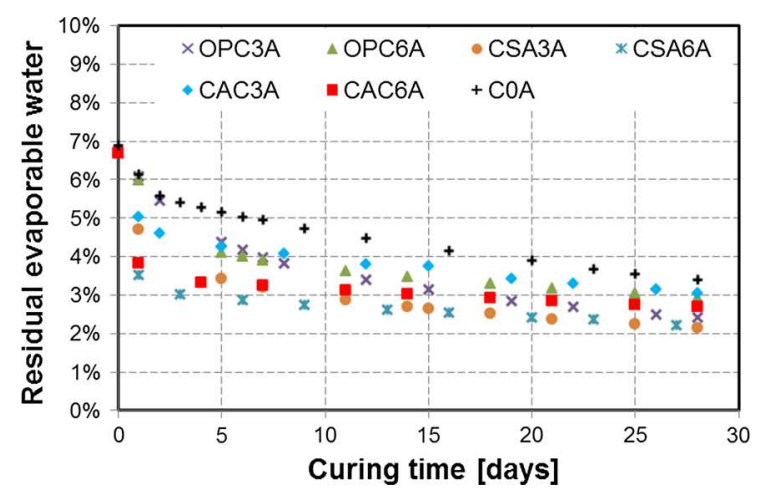

Fig. 10 Evolution of residual evaporable water content

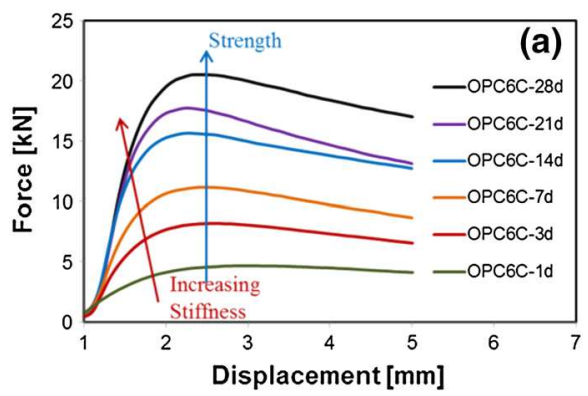

By comparing Fig. 11a and b, it is very clear that cement hydration dominates both the stiffness and stability. Take the Fig. 11a for example, the increases in both stiffness and stability from 1 day to 7 days after mixing are mainly caused by OPC hydration. After 14 dayscuring when most of cement has hydrated, the stiffness kept constant. The further increase in stability was mainly due to drying of water, which allows bitumen to adhere to aggregates. In the case of Fig. 11b, because most CAC has hydrated after 1 day-curing, the stiffness kept constant. The further increase in stability was likely also in this case due to drying of residual evaporable water. These results are in agreement with the residual evaporable water content, which is shown in Fig. 10. We can reasonably infer that on one hand, cement hydrates linked aggregates by forming elastic cross links between them, which consequently increased the stiffness of CBEA [9]. On the other hand, by binding water, cement hydration further increased the stability of CBEA. To gain a deeper understanding of the mechanisms governing the mechanical properties of CBEA, the distribution of hydrated cement and contribution of cement hydrates to the microstructure of CBEA could be imaged by X-ray computed tomography [9] or by scanning electron microscopy (SEM).

The most important contribution of the bitumen emulsions to CBEA is to provide water for the cement hydration and to increase the flexibility of the composite. Based on the results of the present study, it appears that the only effect of bitumen emulsions on cement hydration is some retardation or acceleration.

On the one hand, bitumen emulsion provides water for cement hydration and on the other hand, bitumen forms adheres to aggregates and contributes to the further increase of stability. By quantifying the moisture losses in CBEA, it was found that the residual evaporable water content in the mixtures is

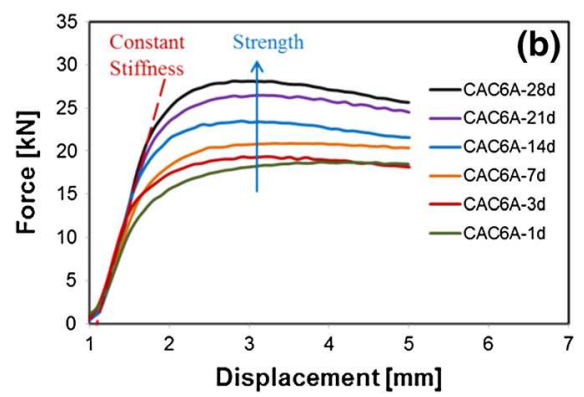

Fig. 11 Force-displacement curve of a OPC6C and b CAC6A as a function of curing time

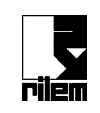


relatively high after 28 days curing (from 1.5 to $3.5 \%$ by mass of mixtures). The slow reduction in moisture content might be the reason for the slow, long-term strength increase in these mixtures [9]. The contribution of bitumen emulsion to the mechanical properties of CBEA cannot be precisely quantified at this stage and needs to be characterized in future studies. This is particularly true with respect to creep, low temperature cracking and fatigue behavior.

\section{Conclusions}

In this study, isothermal calorimetry applied to CBEA mixtures showed that bitumen emulsion may slightly retard or accelerate cement hydration, but has no significant effect on the degree of cement hydration after a couple of days. This paper demonstrates that the early strength of CBEA can be improved by adding small amounts of rapid-hardening cements (CSA and CAC). In addition, CSA and CAC bind more water than OPC, which may lower the stripping and moisture damage potential of CBEA. While cement is considered to be a secondary binder in CBEA, its role appears however to be significant, since cement hydration dominates both the stiffness and stability of CBEA and comparable mechanical properties to hot mix asphalt can be eventually reached by using cementitious materials.

While this paper elucidated some aspects of cement hydration in CBEA, the behavior of bitumen emulsion in the presence of cement and filler is still unclear. The volumetric properties, the distribution of hydrated cement in the microstructure, the durability, the temperature and moisture susceptibility of CBEA also need to be studied.

Acknowledgments The authors thank Hans Kienast, Walter Trindler, Axel Schöler and Dr. Mateusz Wyrzykowski for help with the experiments and CTW Strassenbaustoffe AG for providing bitumen emulsion. The first author was financed by a scholarship from the China Scholarship Council.

\section{References}

1. Swiertz D, Johannes P, Tashman L, Bahia H (2012) Evaluation of laboratory coating and compaction procedures for cold mix asphalt. J Assoc Asph Paving Technol (81):81-107

2. Doyle TA, McNally C, Gibney A, Tabakovic A (2013) Developing maturity methods for the assessment of coldmix bituminous materials. Constr Build Mater 38:524-529
3. Al-Busaltan S, Al Nageim H, Atherton W, Sharples G (2012) Mechanical properties of an upgrading cold-mix asphalt using waste materials. J Mater Civ Eng 24:14841491

4. Al Nageim H, Al-Busaltan SF, Atherton W, Sharples G (2012) A comparative study for improving the mechanical properties of cold bituminous emulsion mixtures with cement and waste materials. Constr Build Mater 36:743748

5. Needham D (1996) Developments in bitumen emulsion mixtures for roads. Ph.D. thesis, University of Nottingham, Nottingham

6. Thanaya INA (2003) Improving the performance of cold bituminous emulsion mixtures incorporating waste materials. Ph.D. thesis, University of Leeds

7. Thanaya INA, Zoorob SE, Forth JP (2009) A laboratory study on cold-mix, cold-lay emulsion mixtures. Proc ICE Transp 162(1):47-55

8. Brown SF, Needham D (2000) A study of cement modified bitumen emulsion mixtures. Assoc Asph Paving Technol Proc 69:92-121

9. Garcia A, Lura P, Partl MN, Jerjen I (2013) Influence of cement and environmental humidity on asphalt emulsion and cement composites performance. Mater Struct 46(8): 1275-1289

10. Li G, Zhao Y, Pang S-S, Huang W (1998) Experimental study of cement-asphalt emulsion composite. Cem Concr Res 28(5):635-641

11. Oruc S, Celik F, Akpinar MV (2007) Effect of cement on emulsified asphalt mixtures. J Mater Eng Perform 16(5): 578-583

12. Schmidt RJ, Santucci LE, Coyne LD (1973) Performance characteristics of cement-modified asphalt emulsion mixes. Assoc Asph Paving Technol Proc 42:300-319

13. Bocci M, Grilli A, Cardone F, Graziani A (2011) A study on the mechanical behaviour of cement-bitumen treated materials. Constr Build Mater 25:773-778

14. Harada Y, Tottori S, Itai N, Noto T (1983) Development of cement-asphalt mortar for slab tracks in cold climate. Railw Tech Res Inst Q Rep 24:62-67

15. Wang F, liu Z, wang T, Hu S (2008) A novel method to evaluate the setting process of cement and apshalt emulsion in CA mortar. Mater Struct 41:643-647

16. Terrel RL, Wang CK (1974) Early curing behaviour of cement modified asphalt emulsion mixtures. Association of Asphalt Paving Technologists annual meeting, AAPT, New York

17. Rutherford T, Wang Z, Shu X, Huang B, Clarke D (2014) Laboratory investigation into mechanical properties of cement emulsified asphalt mortar. Constr Build Mater 65:76-83

18. Pouliot N, Marchand J, Pigeon M (2003) Hydration mechanisms, microstructure, and mechanical properties of mortars prepared with mixed binder cement slurry-asphalt emulsion. J Mater Civ Eng 15:54-59

19. Yao Y, Sun H (2012) Performance and microanalysis of cement asphalt mortar with admixture of coal fly ash. J Mater Sci Res 1(2):193-206

20. Higuchi Y, Harada Y, Sato T, Nakagawa K, Kawaguchi AI, Kasahara Y (1978) Quick hardening cement-asphalt composition. United States Patent 4084981, April 18, pp 1-7 
21. Liu Y, Liu M, Wang F, Hu S (2013) Study on the sulphoaluminate cement-asphalt composite mortar for highspeed railway repair. In: Proceedings of the 1st international conference on sulphoaluminate cement: materials and engineering technology, Wuhan, 23-24 Oct 2013

22. Taylor HFW (1997) Cement chemistry, 2nd edn. Thomas Telford Ltd, London

23. Juenger MCG, Winnefeld F, Provis JL, Ideker JH (2011) Advances in alternative cementitious binders. Cem Concr Res 41:1232-1243

24. Gartner E (2004) Industrially interesting approaches to 'low- $\mathrm{CO}_{2}$ ' cements. Cem Concr Res 34:1489-1498

25. Winnefeld F, Lothenbach B (2012) Hydration of calcium sulfoaluminate cements-experimental findings and thermodynamic modelling. Cem Concr Res 40:1239-1247

26. Winnefeld F, Barlag S (2010) Calorimetric and thermogravimetric study on the influence of calcium sulfate on the hydration of ye'elimite. J Therm Anal Calorim 101:945-957

27. Lura P, Winnefeld F, Klemm S (2010) A method for simultaneous measurements of heat of hydration and chemical shrinkage on hardening cement pastes. J Therm Anal Calorim 101:925-932

28. Chaignat P, Winnefeld F, Lothenbach L, Müller CM (2012) Beneficial use of limestone filler with calcium sulphoaluminate cement. Constr Build Mater 26:619-627

29. Airey GD (2003) Rheological properties of styrene butadiene styrene polymer modified road bitumens. Fuel 82:1709-1719

30. Schindler AK, Folliard KJ (2005) Heat of hydration models for cementitious materials. ACI Mater J 102(1):24-33

31. Powers TC, Brownyard TL (1948) Studies of the physical properties of hardened Portland cement paste, Bulletin 22, vol 43(9). Research Laboratories of the Portland Cement Association, Chicago, pp 249-336

32. Tan Y, Ouyang J, Lv J, Li Y (2013) Effect of emulsifier on cement hydration in cement asphalt mortar. Constr Build Mater 47:159-164

33. Lura P, Winnefeld F, Fang X (2014) A simple method for estimating the amount of water bound by cement. J Therm Anal Calorim

34. Hansen TC (1986) Physical structure of hardened cement paste, a classical approach. Mater Struct 19(6):423-436 